\title{
Use of a novel polyvinyl alcohol membrane as a pericardial substitute reduces adhesion formation and inflammatory response after cardiac reoperation
}

\author{
Pedro Paulo Martins de Oliveira, MD, PhD, ${ }^{\text {a }}$ Vanessa Petrilli Bavaresco, $\mathrm{PhD},{ }^{\mathrm{b}}$ \\ Lindemberg Mota Silveira-Filho, MD, PhD, ${ }^{a}$ Andre Almeida Schenka, MD, $\mathrm{PhD},{ }^{c}$ \\ Karlos Alexandre de Souza Vilarinho, MD, PhD, ${ }^{\mathrm{a}, \mathrm{d}}$ \\ Elaine Soraya Barbosa de Oliveira Severino, $\mathrm{MD}, \mathrm{PhD},{ }^{\mathrm{a}}$ and Orlando Petrucci, $\mathrm{MD}, \mathrm{PhD}^{\mathrm{a}, \mathrm{d}}$
}

Background: Adhesions may increase the incidence of lethal complications of cardiac reoperations, which account for up to $20 \%$ of all open-heart surgeries. Herein, we describe the use of a polyvinyl alcohol membrane (PVAM) as a pericardial alternative and describe its performance during reoperation in a relevant animal model.

\begin{abstract}
Methods: The PVAM samples were reticulated by electron beam radiation and manipulated into a tube shape. After thoracotomy, the pericardium of Wistar rats was opened to expose the heart. Rats were treated by pushing the heart back into the thoracic cavity (Sham group), sprinkling the epicardium with talcum powder (Talc group), encircling the heart with PVAM (PVAM group), or sprinkling the epicardium with talcum powder before placing the PVAM to encircle the heart (PVAM + Talc group). Animals were recovered for 8 weeks and then euthanized. Macroscopic findings (ie, extent and severity of adhesions) were classified according to a 4-grade adhesion scale. The PVAM was tested for direct and indirect cytotoxicity with Vero cells. The water absorption capability and in vivo calcification after 8 weeks of subcutaneous implantation of the membrane were examined. Data were analyzed by analysis of variance and Bonferroni post hoc tests.
\end{abstract}

Results: The PVAM group had lower adhesion scores than the Talc and Sham groups, as well as reduced epicardium thickness and inflammatory cell results, compared with the Talc and PVAM + Talc groups. The PVAM exhibited no direct or indirect cytotoxicity, good water absorption capability $(42.4 \% \pm 0.9 \%)$, and negligible calcification after 8 weeks $\left(4.42 \times 10^{-3} \pm 2.56 \times 10^{-3}\right.$ percentage of the total mass $)$.

Conclusions: The PVAM shows promising properties for its potential use as a novel pericardial substitute. (J Thorac Cardiovasc Surg 2014;147:1405-10)

Pericardial and mediastinal adhesions increase the mortality and morbidity rates after cardiac reoperations. ${ }^{1,2}$ Many individuals with congenital heart defects will require multiple repeat sternotomies. Numerous strategies have been described for reducing postoperative adhesions, such as sprinkling solutions into the pericardial sac or using expanded polytetrafluoroethylene (ePTFE) or bioabsorbable gelatin sheets. ${ }^{3-5}$ However, there is no accepted approach for reducing adhesion formation after cardiac surgery. ${ }^{6}$ Herein, we describe a novel membrane

\footnotetext{
From the Surgery $^{\mathrm{a}}$ and Pharmacology ${ }^{\mathrm{c}}$ Departments, Faculty of Medical Science, the Department of Plastic, ${ }^{b}$ Technical College Campinas, and the Laboratory of Myocardial Ischemia/Reperfusion Injury, ${ }^{d}$ Faculty of Medical Science, State University of Campinas, São Paulo, Brazil.

This work was founded by Fundação de Amparo a Pesquisa de São Paulo.

Disclosures: Authors have nothing to disclose with regard to commercial support.

Received for publication May 20, 2013; revisions received June 27, 2013; accepted for publication July 3, 2013; available ahead of print Aug 29, 2013.

Address for reprints: Orlando Petrucci, MD, PhD, Rua João Baptista Geraldi, 135 Campinas, São Paulo, Brazil, CEP 13085020 (E-mail: petrucci@cardiol.br or orlando@fcm.unicamp.br).

$0022-5223 / \$ 36.00$

Copyright (C) 2014 Published by Elsevier Inc. on behalf of The American Association for Thoracic Surgery

http://dx.doi.org/10.1016/j.jtcvs.2013.07.021
}

assembled from 10\% polyvinyl alcohol (PVA). We examined the use of this PVA hydrogel membrane (PVAM) as a pericardial substitute in an animal model of adhesion formation, focusing on its cytotoxic effects and inflammatory potential.

\section{METHODS \\ Assembling the PVAM}

The PVAM was made as described previously. ${ }^{7}$ Briefly, the membrane was assembled from an aqueous solution of 10\% PVA (Sigma Aldrich, São Paulo, Brazil), which was kept at room temperature for 7 days until dry. The dried membrane was $2-\mathrm{mm}$ thick, and it was manipulated into a tube-like shape (1.5-cm height and 0.5 -cm internal diameter).

The PVAM was subjected to a cross-linking step to stabilize the polymer and prevent its dissolution in contacted fluids. This step has prevented PVAM dissolution for at least 24 weeks after implantation in bone tissue. ${ }^{7}$ Electron beam irradiation, which can simultaneously accomplish the reticulation and sterilization of the membranes, was performed for the cross-linking step. Before irradiation, the material was acetylated by immersion in a solution of $40 \%$ formaldehyde, $50 \%$ sulfur acid, and $300 \mathrm{~g}$ of anhydrous sodium sulfate at $60^{\circ} \mathrm{C}$ for 24 hours. The PVAMs were washed to remove any residual chemical and stored in distilled water. The membranes were cross-linked by electron beam irradiation with 25 kGy using a Radiation Dynamics electron beam accelerator (Instituto de Pesquisas Energéticas e Nucleares, São Paulo). After this process, the PVAMs were considered to be sterilized and ready for use. 


\section{Abbreviations and Acronyms}

$\mathrm{CMC}=$ carboxymethylcellulose

ePTFE $=$ expanded polytetrafluoroethylene

PVAM $=$ polyvinyl alcohol membrane

\section{Surgical Protocol}

Ethical approval was obtained from the local institutional review board. All animal handling and experiments were performed in accordance with the standards of the Brazilian Council for Animal Experimentation and the 1996 Guide for the Care and Use of Laboratory Animals, published by the National Institutes of Health. Animals were maintained under specific pathogen-free conditions, a 12-hour/12-hour light/dark cycle, and a room temperature of $21^{\circ} \mathrm{C}$.

Four-week-old male Wistar rats (average weight, $300 \mathrm{~g}$ ) were anesthetized with $2 \%$ isoflurane. A left thoracotomy was performed, the pericardium was opened, and the heart was exposed. Animals were randomized into 4 groups (10 animals per group). In the Sham group, the heart was pushed back to the thoracic cavity, and the incision was closed. In the Talc group, talcum powder $(10 \mathrm{mg})$ was sprinkled over the epicardium. In the PVAM group, a PVAM tube was inserted into the thoracic cavity and used to encompass the heart from the surrounding tissue, except for where the major vessels exited/entered the heart. Finally, in the PVAM + Talc group, talcum powder $(10 \mathrm{mg})$ was sprinkled over the epicardium, and then a PVAM tube was inserted into the thoracic cavity and used to encompass the heart completely. No sutures were needed to hold the PVAM tube in place, because of its flexibility and the limited nature of the thoracic space.

All animals were recovered from anesthesia for 8 weeks, during which time they were provided standard chow and water ad libitum. Eight weeks after the surgical protocol, the animals were euthanized with an intravenous dose of pentobarbital, the thoracic cavity was opened, and any adhesions were lysed. Two observers (P.P.M.O. and V.P.B.), blinded to each other, scored the adhesions from 0 to 3 , according to an adaptation of the score described by Kajihara and colleagues ${ }^{8}: 0$, absence of adhesions; 1 , weak adhesions that are easily lysed; 2 , moderate adhesions that are lysed with dissection; and 3, severe adhesions that require sectioning by scissors for removal. In all animals, the PVAM tube was inspected for its correct position involving the heart.

\section{Histologic Assessment}

Cardiac tissue was fixed in $10 \%$ paraformaldehyde, embedded in paraffin, cut into slices, and stained with hematoxylin and eosin. For the inflammatory cell count and epicardial thickness assessments, a midportion of the left ventricle (ie, at the papillary muscle level) was used in all animals. A blinded observer randomly chose 3 optical fields ( $40 \times$ magnification) to evaluate the inflammatory cell count and the epicardial thickness.

\section{Physical and Biological Characteristics of the PVAMs}

Indirect and direct cytotoxicity assays were performed with an African green monkey epithelial kidney cell line (Vero cells; Instituto Adolfo Luftz, São Paulo). To assess the indirect cytotoxicity, PVAMs $(0.2 \mathrm{~g} / \mathrm{mL})$ in the liquid state without cross-linking were mixed in HAM F-10 media (Sigma Aldrich) containing 10\% fetal bovine serum (Nutricell, Campinas, Brazil) at $37^{\circ} \mathrm{C}$. Different concentrations of the membrane solution were added to cell media containing $3 \times 10^{5}$ cells $/ \mathrm{mL}$. After 24 hours, the cell viability was assessed with the (dimethylthiazol-2-yl)-2,5-diphenyltetrazolium bromide colorimetric method at $550 \mathrm{~nm} .{ }^{9}$ The negative control was an extract of $2 \%$ polystyrene in a solution of $10 \%$ bovine serum albumin and $10 \%$ phenol.

To assess the direct cytotoxicity, Vero cells were seeded and grown over reticulated and sterilized PVAMs. HAM F-10 media containing 10\% fetal bovine serum was added, and the cells were grown at $37^{\circ} \mathrm{C}$ for 24 hours. Cell viability was assessed by the MMT (3-[4,5-dimethylthiazol-2-yl]2,5- diphenyltetrazolium bromide; thiazolyl blue) colorimetric method. ${ }^{9}$ Two controls were used: a positive control, containing $10 \%$ phenol in the media for 24 hours; and a negative control, containing only media.

The hydration capacity of the membranes was evaluated with dry samples of PVAM immersed in distilled water until a stable membrane weight was reached. Five measurements were made, and the hydration capacity was expressed as a percentage. The in vivo calcification index was determined by implanting a PVAM $\left(1 \mathrm{~cm}^{2}\right)$ subcutaneously (s.c.) on

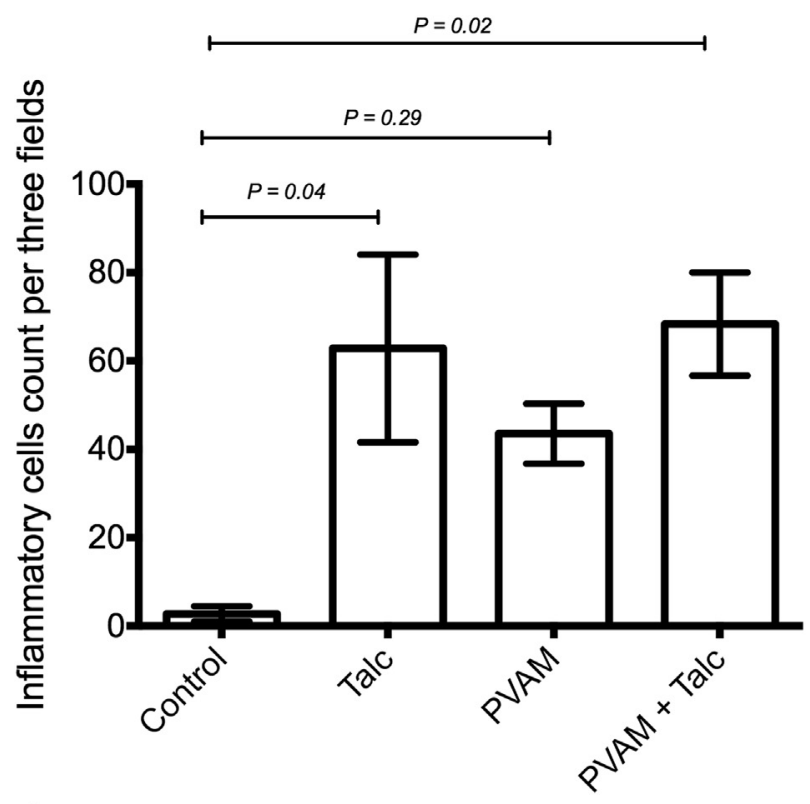

A
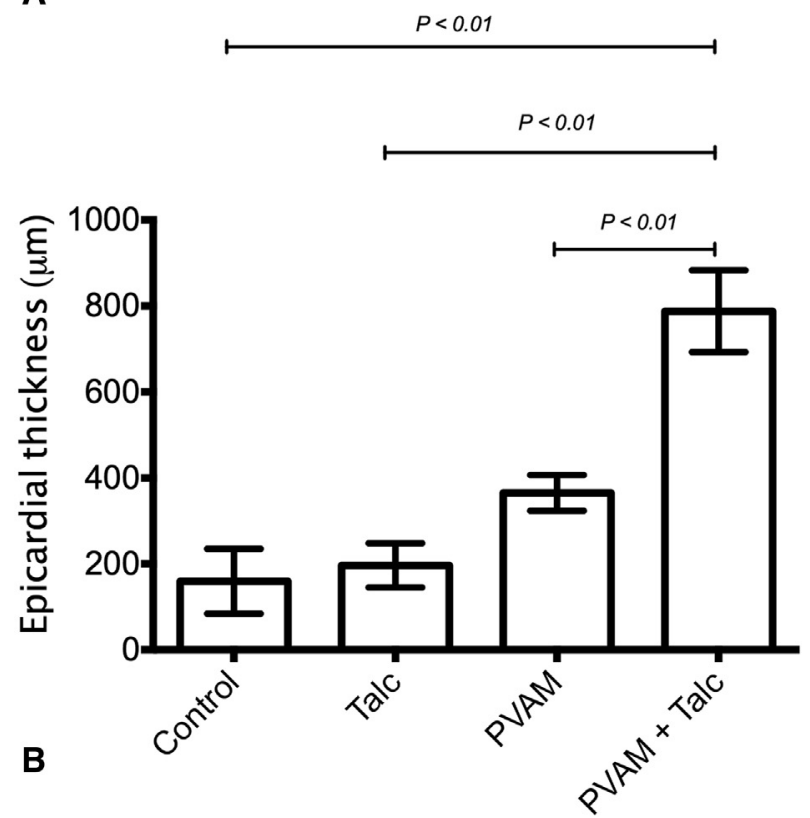

FIGURE 1. Inflammatory cell count (A) and epicardial thickness (B) in all 4 groups after 8 weeks of observation. Bar height indicates mean, with error bar showing standard error of mean. $P$ values by analysis of variance with post hoc Bonferroni for multiple comparisons. PVAM, Polyvinyl alcohol membrane. 

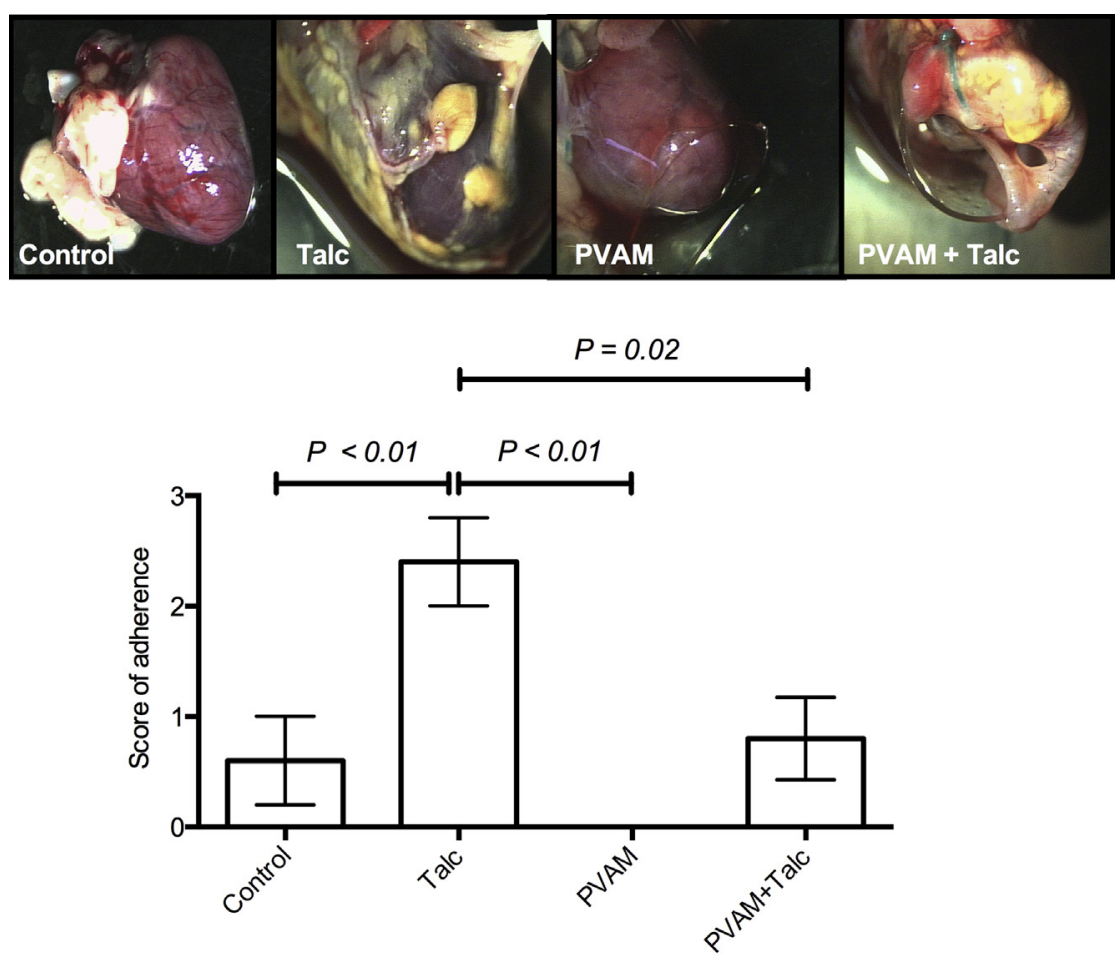

FIGURE 2. Representative images of pericardial adhesions (top) and the average adhesion scores (bottom) in each of the 4 groups 8 weeks after treatment $(\mathrm{n}=10$ animals in each group). Bar height indicates mean, with error bars showing standard error of mean. $P$ values by analysis of variance with post hoc Bonferroni for multiple comparisons. PVAM, Polyvinyl alcohol membrane.

the dorsal segment of a Wistar male rat $(\mathrm{n}=10)$. Eight weeks after implantation, the animals were euthanized, and the membrane calcium content was assessed with $\mathrm{x}$-ray fluorescence analysis. The membranes were dried at room temperature and inserted into an $\mathrm{x}$-ray fluorescence spectrometer (EDX 700; Shimadzu, Columbia, Md). The AXIL software package (IAEA Laboratories, Seibersdorf, Austria) was used to determine the calcium content, which was expressed as a percentage of the total mass of the material analyzed.

\section{Statistical Analysis}

All values are reported as means with SDs. Categorical variables are expressed as frequencies. An analysis of variance with the post hoc Bonferroni test was used for multiple comparisons. Differences with $P<.05$ were considered statistically significant. The GraphPad Prism, version 6 , software package was used for all analyses (GraphPad Software, La Jolla, Calif).

\section{RESULTS}

The average membrane hydration capacity was $42.4 \% \pm$ $0.89 \%$. The average calcium content of PVAMs after 4 weeks of s.c. implantation was $4.42 \times 10^{-3} \pm$ $2.56 \times 10^{-3}$ percentage of the total mass. The number of inflammatory cells was similar between the Sham and PVAM groups and was generally less than the number observed in the Talc and PVAM + Talc groups (Figure 1, $A)$. The epicardial thickness was similar between the Sham, Talc, and PVAM groups and was thinner than the epicardium in the PVAM + Talc group $(P<.001)$ (Figure $1, B)$. No adhesion was observed in any animal in the PVAM group, which was a significant result compared with the other groups (Figure 2). The PVAMs did not demonstrate direct or indirect cytotoxic effects (Figure 3).

\section{DISCUSSION}

Adhesions offer a major challenge in cardiac surgery reoperations, especially for planned reoperations, such as in patients with congenital heart defects. ${ }^{10,11}$ Various materials have been developed for diminishing pericardial adhesions, such as resorbable collagen membranes, biodegradable collagen-elastin membranes, propylene oxide-treated bovine pericardium, and bioabsorbable gelatin sheets. ${ }^{5,7,12-14}$ Herein, we evaluated a novel PVA membrane as a pericardial substitute. In vitro, the PVAM showed a high hydration capacity and no cytotoxic effect after direct or indirect contact with cultured cells. After 8 weeks of s.c. implantation in rats as a pericardial substitute, the PVAMs showed a low calcification index and a low inflammatory effect. In these rats, few adhesions were observed between the epicardium and the surrounding structures of the thoracic cavity. Although PVA-based materials have been used in other biomedical applications, ${ }^{7}$ to the best of our knowledge, this report represents the first time that a PVA membrane has been used as a pericardial substitute.

Our findings are consistent regarding the method used, with adhesion scores and microscopic findings obtained 

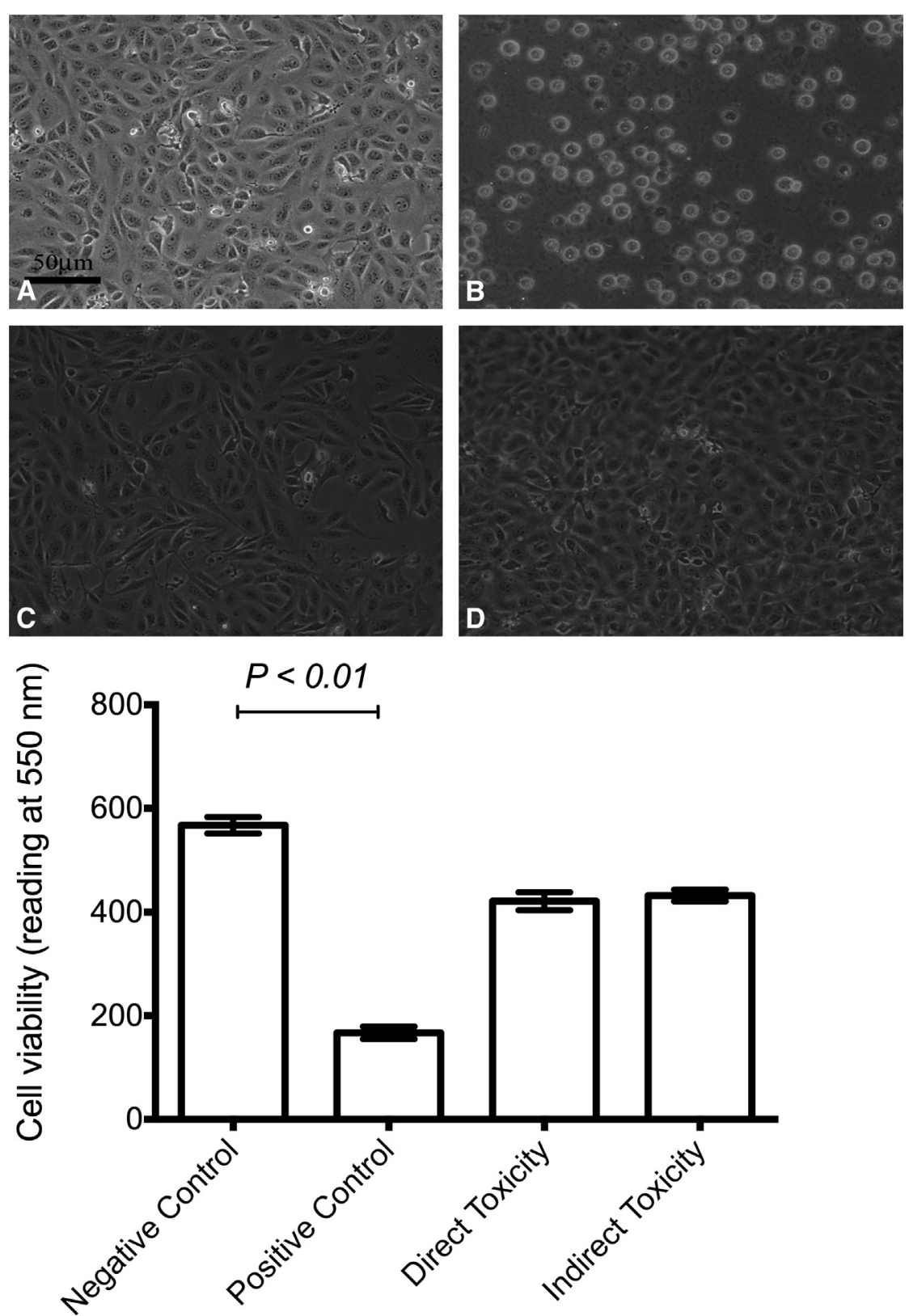

FIGURE 3. Results of direct and indirect cytotoxicity tests after 24 hours of cell growth in the 4 groups. Confluence of cells in the negative control (A) and the positive control (B). Confluence of cells under conditions of direct toxicity (C) and indirect toxicity (D). Bar height indicates mean, with error bars showing standard error of mean. $P$ values by analysis of variance with post hoc Bonferroni for multiple comparisons.

by a blinded observer. Previous reports have used similar methods with different membranes or biodegradable materials. ${ }^{8,14-16}$ Although we did not compare the PVAM with any commercially available membrane, we found promising results compared with Bel and colleagues, ${ }^{17}$ who reported similar adhesion scores using a sheep model with an absorbable collagen membrane after 8 weeks of implantation. In the present study, we observed almost no adhesions between the PVAM-protected epicardium and the adjacent thoracic structures after 8 weeks of implantation.
A polyvinyl alcohol with carboxymethylcellulose (PVA/ CMC) hydrogel has been used in different tissues. ${ }^{18,19}$ Slieker and colleagues ${ }^{19}$ evaluated use of the PVA/CMC hydrogel as an adhesion barrier in colon anastomoses. They found that the hydrogel did not interfere with healing of the anastomotic site and did not prevent adhesion formation. The neutral effect reported by Slieker and colleagues ${ }^{19}$ regarding adhesion formation might be due to the hydrogel format of the PVA/CMC. In particular, the hydrogel was completely absorbed after 3 to 4 weeks and eliminated via urinary excretion. The hydrogel format 
also meant that the precise localization of the PVA/CMC at the anastomotic site was not ensured. ${ }^{19}$ In the present study, at 8 weeks after its implantation, the tube-shaped PVAM was not absorbed and continued to maintain its position encompassing the heart. The cross-linking process used during membrane assembly ensured that a stable membrane could be maintained for at least 24 weeks after bone tissue implantation. ${ }^{7}$

In another study, Slieker and colleagues evaluated use of the PVA/CMC hydrogel in a rat model of peritonitis, ${ }^{18}$ finding that the PVA/CMC hydrogel reduced adhesions in the viscera compared with the control group. This result may be because of the nature of hydrogel, which might distribute more homogenously between the peritoneum and abdominal viscera. ${ }^{18}$ In a swine model of chronic ischemia, Lassaletta and colleagues ${ }^{20}$ showed that alcohol use had beneficial effects on precluding adhesion formation between the pericardium and epicardium. They simulated coronary ischemia with an aneroid constrictor to induce chronic coronary insufficiency. The animals were fed a high-cholesterol diet supplemented with either vodka or red wine. The experimental group that received vodka exhibited fewer pericardial adhesions, less intramyocardial fibrosis, and reduced C-reactive protein levels, indicating a lower inflammatory response. ${ }^{20,21}$

In our study, the PVAM group showed a low inflammatory cell density compared with the other groups. Inflammatory cells play important roles in the healing process and may increase the presence of adhesions. ${ }^{13}$ We used talcum powder as an irritant agent for better evaluation of the PVAM properties. Interestingly, we observed that the PVAM + Talc group showed a similar adhesion score to the control group. This indirect observation may indicate that the PVAM protected the surrounding tissues from the talcum powder that was sprinkled over the epicardium. Virtually, the only adhesions that did occur were observed inside the PVAM tube, which was created to simulate the pericardial membrane (Figure 2).

Our study had some limitations. The model may not simulate all postoperative and thoracic reentry scenarios after cardiopulmonary bypass. Talcum was used as an irritant factor in the absence of blood in the pericardium. This situation does not reflect the true scenario after an open-heart surgery. As a result, the rate of adhesion formation in this model may have been decreased compared with the clinical situation. ${ }^{13}$ Despite the differences observed among the groups, the period of 8 weeks is short, and reoperations within 4 weeks are infrequent. Finally, the mechanism by which PVAM prevented adhesion formation is not clear and will require further investigation. Despite these limitations, it was evident that the PVAM elicited little inflammatory response and precluded the occurrence of adhesions.
The PVAM offers several clinical advantages, in terms of its transparency, malleability, elasticity, and possibility of being sewn into the mediastinum. Some of the commercially available membranes are bovine or porcine derived, which may elicit an inflammatory response or adhesion formation. ${ }^{10,17}$ Others, such as those made of ePTFE, are not transparent and have limited malleability compared with the PVAM. Our findings offer the possibility of a new membrane for use as a pericardial substitute before planned reoperations, especially in newborns and infants who are more likely to have several surgical interventions in their pathway for a definitive surgical treatment. This new membrane may contribute to reduce the occurrence of adverse events, especially in patients with planned reintervention because of the nature of their initial disease. $^{22-25}$

\section{CONCLUSIONS}

The use of PVA membranes reduces the occurrence of adhesions and promotes fewer epicardial reactions, which may facilitate later reoperation.

\section{References}

1. Yau TM, Borger MA, Weisel RD, Ivanov J. The changing pattern of reoperative coronary surgery: trends in 1230 consecutive reoperations. J Thorac Cardiovasc Surg. 2000;120:156-63.

2. Follis FM, Pett SB Jr, Miller KB, Wong RS, Temes RT, Wernly JA. Catastrophic hemorrhage on sternal reentry: still a dreaded complication? Ann Thorac Surg. 1999;68:2215-9.

3. Kajiwara H, Hamada T, Ichikawa Y, Ishi M, Yamazaki I. Experience with expanded polytetrafluoroethylene (ePTFE Gore-Tex) surgical membrane for coronary artery grafting: does ePTFE surgical membrane predispose to postoperative mediastinitis? Artif Organs. 2004;28:840-5

4. Wang ND, Doty DB, Doty JR, Yuksel U, Flinner R. BioGlue: a protective barrier after pericardiotomy. J Card Surg. 2007;22:295-9.

5. Yoshioka I, Saiki Y, Sakuma K, Iguchi A, Moriya T, Ikada Y, Tabayashi K. Bioabsorbable gelatin sheets latticed with polyglycolic acid can eliminate pericardial adhesion. Ann Thorac Surg. 2007;84:864-70.

6. Lodge AJ, Wells WJ, Backer CL, O'Brien JE Jr, Austin EH, Bacha EA, et al. A novel bioresorbable film reduces postoperative adhesions after infant cardiac surgery. Ann Thorac Surg. 2008;86:614-21.

7. Batista NA, Rodrigues AA, Bavaresco VP, Mariolani JR, Belangero WD. Polyvinyl alcohol hydrogel irradiated and acetalized for osteochondral defect repair: mechanical, chemical, and histological evaluation after implantation in rat knees. Int J Biomaterials. 2012;2012:582685.

8. Kajihara N, Eto M, Oishi Y, Boku N, Kuwahara K, Nishiguchi N, et al. Three-layered synthetic pericardial substitutes reduce postoperative pericardial adhesions. J Thorac Cardiovasc Surg. 2005;129:18-24.

9. Stockert JC, Blazquez-Castro A, Canete M, Horobin RW, Villanueva A. MTT assay for cell viability: intracellular localization of the formazan product is in lipid droplets. Acta Histochem. 2012;114:785-96.

10. Eng J, Ravichandran PS, Abbott CR, Kay PH, Murday AJ, Shreiti I. Reoperation after pericardial closure with bovine pericardium. Ann Thorac Surg. 1989;48: 813-5.

11. Lahtinen J, Satta J, Lahde S, Suramo I, Nissinen J, Pokela R, Juvonen T. Computed tomographic evaluation of retrosternal adhesions after pericardial substitution. Ann Thorac Surg. 1998;66:1264-8.

12. Oray BN, Kelly S, Konobeck T, Lambert A, Mooradian DL. Novel propylene oxide-treated bovine pericardium as soft tissue repair material and potential scaffold for tissue engineering. Surg Technol Int. 2009;18:47-54.

13. Bel A, Kachatryan L, Bruneval P, Peyrard S, Gagnieu C, Fabiani JN, Menasche P. A new absorbable collagen membrane to reduce adhesions in cardiac surgery. Interact Cardiovasc Thorac Surg. 2010;10:213-6. 
14. Florez S, Herreros JM, Bustamante J, Tamayo E. Biodegradable collagen-elastin membrane as a pericardial substitute in coronary surgery. Rev Esp Cardiol. 2010; 63:1209-10.

15. Mitchell JD, Lee R, Neya K, Vlahakes GJ. Reduction in experimental pericardial adhesions using a hyaluronic acid bioabsorbable membrane. Eur J Cardiothorac Surg. 1994;8:149-52.

16. Sakuma K, Iguchi A, Ikada Y, Tabayashi K. Closure of the pericardium using synthetic bioabsorbable polymers. Ann Thorac Surg. 2005;80: $1835-40$.

17. Bel A, Ricci M, Piquet J, Bruneval P, Perier MC, Gagnieu C, et al. Prevention of postcardiopulmonary bypass pericardial adhesions by a new resorbable collagen membrane. Interact Cardiovasc Thorac Surg. 2012;14: 469-73.

18. Deerenberg EB, Mulder IM, Ditzel M, Slieker JC, Bemelman WA, Jeekel J, Lange JF. Polyvinyl alcohol hydrogel decreases formation of adhesions in a rat model of peritonitis. Surg Infect. 2012;13:321-5.

19. Slieker JC, Ditzel M, Harlaar JJ, Mulder IM, Deerenberg EB, BastiaansenJenniskens YM, et al. Effects of new anti-adhesion polyvinyl alcohol gel on healing of colon anastomoses in rats. Surg Infect. 2012;13:396-400.
20. Lassaletta AD, Chu LM, Sellke FW. Effects of alcohol on pericardial adhesion formation in hypercholesterolemic swine. J Thorac Cardiovasc Surg. 2012; 143:953-9.

21. Lassaletta AD, Chu LM, Elmadhun NY, Robich MP, Hoffman ZG, Kim DJ, Sellke FW. Mechanism for reduced pericardial adhesion formation in hypercholesterolemic swine supplemented with alcohol. Eur J Cardiothorac Surg. 2013; 43:1058-64.

22. Calvaruso DF, Rubino A, Ocello S, Salviato N, Guardi D, Petruccelli DF, et al. Bidirectional Glenn and antegrade pulmonary blood flow: temporary or definitive palliation? Ann Thorac Surg. 2008;85:1389-95; discussion 95-6.

23. Nakano T, Fukae K, Sonoda H, Tachibana T, Kajimoto M, Ando Y, Kado H. Follow-up study of pulmonary artery configuration in hypoplastic left heart syndrome. Gen Thorac Cardiovasc Surg. 2008;56:54-61.

24. Petrucci O, Khoury PR, Manning PB, Eghtesady P. Outcomes of the bidirectional Glenn procedure in patients less than 3 months of age. J Thorac Cardiovasc Surg. 2010;139:562-8.

25. Petrucci O, O’Brien SM, Jacobs ML, Jacobs JP, Manning PB, Eghtesady P. Risk factors for mortality and morbidity after the neonatal Blalock-Taussig shunt procedure. Ann Thorac Surg. 2011;92:642-51. 